Over-identification $v$. under-identification. There is an understandable tendency for all doctors, including psychiatrists, to anticipate what the court may decide in a particular case. A class bias or a personal bias can, and sometimes does, enter professional medical reports. For example, medical evidence may be influenced, perhaps less than consciously, by the reporter's personal views on the appropriateness or otherwise of harsh sentencing for defendants from social class 1 . Sexual offenders frequently elicit angry responses that can translate into biased reporting also. Over-identification can also be problematic either with the subject or with what some refer to as "the control apparatus" (courts, prisons, the Gardai, even psychiatry itself). The medical function does not of course include suggesting or influencing sentencing policy, and recommendations such as "there is little to be gained from sentencing this man" etc. should be avoided.

Changing sides. If examination of a subject uncovers material detrimental to the case and, ipso facto, beneficial to the other side, crossing over or changing sides is not ethically permissible. A problem can arise where the treating psychiatrist is asked to join the state prosecutor against his patient. He should refuse and only give evidence if subpoenaed, making the court aware of his ethical dilemma.

The reports of other experts. Occasionally one is asked by Counsel or by a solicitor to comment on descriptions, terms or conclusions in reports submitted by colleagues and other professions. The nature of psychiatric testimony obviously may involve the reports of psychologists and social workers but there is enough dilemma attached to explaining and justifying one's own professional opinion without making intrusions into the reports of colleagues, and invitations to do this should be resisted.

The question of hearsay evidence. Much of psychiatric evidence can be classified as hearsay. However, such evidence is seldom challenged on these grounds.
Psychiatric diagnosis is not based solely on what the patient says - rather it is based on the totality of interviewing and observing and piecing together all the information.

In ordinary professional practice the collection of background data is frequently delegated to professional colleagues. Psychiatrists frequently use reports from social worker and psychologist colleagues to complete a diagnostic formulation. Where serious charges are brought it may generally be recommended that the doctor should base his report as much as possible on information elicited personally. Being thorough in this matter may mean spending a lot of time on essentials including home visiting and family interviewing rather than depending on reports from other professionals. Where parts of a psychiatric report are based on information collected by others this should be clearly indicated in the report itself.

Reporting without direct examination. Occasionally psychiatrists may be requested to give an opinion without having the opportunity to examine the individual in question. For example, testamentary capacity may be challenged after death and firm opinions expressed about ante mortem psychopathology based on case notes etc. Where the subject is living and refusing examination a special dilemma may arise. This is a contentious area and the main obligation of the reporting psychiatrist is to clarify the circumstances of his report and the consequent limitations of his conclusions quite clearly. No hard and fast rules can be laid down in this area, especially in unusual instances where case records have been impounded by the court. There is of course a difference between clearly recorded facts indicating major psychiatric illness and mental handicap as opposed to documentation of "soft" and relatively unreliable diagnostic concepts such as personality disorder where inter rater reliability on diagnosis is notoriously low. Opinions can still be given in these cases but the limitations of professional conclusions should be highlighted for the court.

\title{
Induction course for new tutors
}

A one-day induction course intended for newly-recognised tutors, and those in the process of applying for College recognition, will be held at the College on 24 April 1989. Further details can be obtained from $\mathrm{Dr}$ Claire Sillince, c/o The Education Department at the College. 